\title{
Hemodynamic changes during posterior epilepsies: an EEG-fNIRS study
}

Running title: EEG-fNIRS study of posterior epilepsies

Philippe Pouliot ${ }^{\mathrm{a}, \mathrm{b}, *}$, Thi Phuoc Yen Tran ${ }^{\mathrm{c}}$, Véronica Birca ${ }^{\mathrm{c}}$, Phetsamone Vannasing ${ }^{\mathrm{d}}$, Julie Tremblay ${ }^{\mathrm{d}}$, Maryse Lassonde ${ }^{\mathrm{d}, \mathrm{e}}$, Dang Khoa Nguyen ${ }^{\mathrm{c}}$

${ }^{a}$ Département de génie électrique, École Polytechnique de Montréal, C.P.6079, Succ. Centre-ville, Montréal, Qc, Canada HЗCЗA7

${ }^{b}$ Institut de cardiologie de Montréal, Centre de recherche, 5000 Rue Bélanger Est, Montréal, Qc, Canada H1T1C8

'Service de neurologie, Hôpital Notre-Dame du CHUM, 1560 Rue Sherbrooke Est, Montréal, Qc, Canada H3L4M1

${ }^{d}$ Centre de recherche, Hôpital Sainte-Justine, 3175 Chemin de la côte-Sainte-Catherine, Montréal, Qc, Canada H3T1C5

${ }^{e}$ Centre de recherche en neuropsychologie et cognition, Département de psychologie, Université de Montréal, Montréal, Qc, Canada H3C3J7

${ }^{*}$ Corresponding author; Tel.: +1-514-340-4711x2306; fax: +1-514-340-4611; e-mail: ph.pouliot@gmail.com 


\begin{abstract}
Posterior epilepsies are relatively rare, mainly suspected clinically by the presence of visual auras. Functional near-infrared spectroscopy (fNIRS) is an emerging non-invasive imaging technique that has the potential to monitor hemodynamic changes during epileptic activity. Combined with electroencephalography (EEG), 9 patients with posterior epilepsies were recorded using EEG-fNIRS with large sampling (19 EEG electrodes and over 100 fNIRS channels). Spikes and seizures were carefully marked on EEG traces, and convolved with a standard hemodynamic response function for general linear model (GLM) analysis. GLM results for seizures (in 3 patients) and spikes (7 patients) were broadly sensitive to the epileptic focus in $7 / 9$ patients, and specific in $5 / 9$ patients with fNIRS deoxyhemoglobin responses lateralized to the correct lobe, and to plausible locations within the occipital or parietal lobes. This work provides evidence that EEG-fNIRS is a sensitive technique for monitoring posterior epileptic activity.
\end{abstract}

Key words: EEG-fNIRS, occipital lobe epilepsy, seizures, epileptic spikes, hemodynamic response Abstract: 142 words

Text: 2783 words

Numbers of references: 28

Number of text pages: 10

Number of tables: 3

Number of figures: 4

Supplementary Data: 1 table, 7 figures, 2 movies

All authors report no disclosures. 
Pouliot et al. 3

The study is not industry-sponsored. 


\section{INTRODUCTION}

Functional near-infrared spectroscopy (fNIRS) is an emerging technique that uses near-infrared light to non-invasively monitor oxyhemoglobin $(\mathrm{HbO})$, deoxyhemoglobin $(\mathrm{HbR})$, and total hemoglobin $(\mathrm{HbT}$, as a proxy to cerebral blood volume, CBV) changes in the cortex (Irani et al., 2007). Unlike ictal single photon emission computed tomography (SPECT), which can only provide a single perfusion brain image of cerebral blood flow (CBF) during a seizure, combined EEG-fNIRS offers a continuous method of studying regional hemodynamic and oxygenation changes occurring before, during and after seizures (Henry and Van Heertum, 2003; Irani et al., 2007). Using this technique, we previously reported our initial observations on temporal lobe seizures (Nguyen et al., 2012), frontal lobe seizures (Nguyen et al., 2013) and interictal focal spikes (Peng et al., 2013). With temporal lobe complex partial seizures, an expected significant increase in $\mathrm{CBV}$ and $\mathrm{HbO}$ was observed but also a surprising gradual rise in $\mathrm{HbR}$ suggesting that the increase in $\mathrm{HbO}$ was unable to meet all the ictal metabolic demand. With frontal lobe seizures (classically of shorter duration and with less frequent postictal confusion), similar ictal increases in $\mathrm{HbO} / \mathrm{HbR}$ were observed while $\mathrm{HbR}$ behaved more heterogeneously (increase, decrease or no change). As for interictal epileptic spikes (which generate a weaker neurovascular response than seizures), congruent hemodynamic responses could be detected with EEG-fNIRS (using appropriate analytical tools) when they were present in sufficient number and originated from the superficial neocortex (Peng et al., 2013).

Posterior epilepsies (i.e. occipital, parieto-occipital or temporo-occipital epilepsies) have been less well studied than temporal or frontal lobe epilepsies. Posterior lobe epilepsies are mainly characterized by visual symptoms (e.g. flashing lights), abnormal eye movements with or without subsequent altered consciousness, automatisms or motor manifestations depending on propagation of epileptic activity 
(Adcock and Panayiotopoulos, 2012; Panayiotopoulos, 1999; Tandon et al., 2009; Williamson et al., 1992). Postictally, patients can complain of headaches and transient visual field deficits (Panayiotopoulos, 1999). Electroencephalographic (EEG) recordings show rhythmic activity in occipital regions with variable spread to surrounding posterior regions, temporal structures or even frontal areas (Duncan et al., 1997; Jenssen et al., 2011). Ictal SPECT can reveal activation in posterior areas but also falsely localizing temporal or frontal lobe activations from seizure propagation (Henry and Van Heertum, 2003; Oliveira et al., 1999; Van Paesschen, 2004). As a follow-up to our temporal (Nguyen et al., 2011) and frontal (Nguyen et al., 2013) lobe seizure studies, we report here our observations from EEG-fNIRS recordings of posterior epilepsies.

\section{METHODS}

\section{Subjects}

Participants were recruited from the Notre-Dame epilepsy clinic. Informed consents were obtained from all patients after approval from the Sainte-Justine and Notre-Dame Hospitals' Ethics Committee. All candidates had previously undergone video-EEG monitoring, cerebral magnetic resonance imaging (MRI), and a physical examination for clinical purposes. Additional tests for certain candidates included ictal SPECT, positron emission tomography (PET), magnetoencephalography (MEG), simultaneous EEG-fMRI and an intracranial study. Localization of the most plausible epileptic focus region was carried out by an epileptologist (DKN), based on multimodal analysis of these clinical, electrophysiological, structural and functional imaging data.

\section{Combined EEG-fNIRS recording}

Detailed description of our EEG-fNIRS technique has been reported previously (Nguyen et al., 2012). In summary, up to 64 emitting fiber sources were mounted on a drilled helmet to shed two near-infrared 
wavelengths, one more sensitive to $\mathrm{HbR}(690 \mathrm{~nm})$, the other more sensitive to $\mathrm{HbO}(830 \mathrm{~nm})$. After penetration through the skull and superficial cortex and absorption by chromophores (e.g. HbO and $\mathrm{HbR})$, backscattered light is captured by 16 fiber collectors strategically positioned at $3-5 \mathrm{~cm}$ from the emitting sources. Nineteen EEG electrodes were also mounted onto the helmet according to the 10-20 system for simultaneous EEG recording. Combined EEG-fNIRS recordings were carried out for one or two hours. EEG data were acquired using a sampling rate of $500 \mathrm{~Hz}$ and bandpass filtered between 0.1 $100 \mathrm{~Hz}$ with a $60 \mathrm{~Hz}$ notch filter using a Neuroscan Synamps 2TM system (Compumedics, USA). fNIRS measurements were acquired with a multi-channel Imagent Tissue Oxymeter (ISS Inc., Champaign, Ill, USA). The ISS Oxymeter uses a frequency-domain method which implies that light sources were intensity modulated over time at $110 \mathrm{MHz}$. The optical intensity (DC), modulation amplitude (AC) and phase changes in the collected light data were sampled at $19.5 \mathrm{~Hz}$. Only the DC optical intensity was used for analysis. After the recording session, the location of each optical fiber and fiducial point was digitized and recorded for precise alignment of fNIRS data with the anatomical MRI of each patient.

\section{Data analysis}

EEG data were first viewed by an epilepsy fellow (TPYT) and then reviewed by an epileptologist $(\mathrm{DKN})$ in order to mark all interictal spikes as well as electrical onset and offset of seizures. Because Patients 1 and 2 experienced only brief and mild seizureswithout clear scalp electrographic changes, they were instructed to lift their index finger (if possible) when feeling their aura and rest it back down (if possible) when the seizure was over, and therefore the video was also carefully reviewed to mark their clinical onsets and offsets.

The measured light attenuation data were related to changes in absorption by using a modified BeerLambert law. These absorption changes gave rise to hemoglobin concentrations by using spectral 
extinction curves. The obtained values reflect relative changes of $\mathrm{HbO}$ and $\mathrm{HbR}$ chromophores in the brain.

GLM analyses were performed in the standard manner (Cohen-Adad et al., 2007; Machado et al., 2011; Peng et al., 2013; Pouliot et al., 2012; Ye et al., 2009) by convolving the onset times of epileptic spikes and seizures with a hemodynamic response function (HRF). When spikes arise in a temporally clustered way, nonlinearities could be important (Pouliot et al., 2012)). Thus the leading order nonlinear effect was included as an additional regressor in the GLM, for patients satisfying the rule of thumb that spikes occurred at a rate greater than 100 spikes per 15 minute recording session. A partial component analysis (PCA) filter was performed, consisting in setting to zero the 5 largest eigenvalues in the decomposition over channels. This was observed in (Peng et al., 2013) to yield similar results to setting only the largest eigenvalue to zero. Either of the two PCA filters led to more congruent results than not performing a PCA at all. Temporal filters were also applied: by convolving the data with the HRF for the low pass and applying an order 2 Butterworth at $0.01 \mathrm{~Hz}$ for the high pass. Assuming a $95 \%$ confidence level, the least stringent of the Euler Characteristic (EC) (Li et al., 2012) and Bonferroni thresholds, as well as a weaker threshold of 3.0 (chosen as a proxy to a peak false discovery rate (FDR) threshold, and corresponding to an uncorrected threshold of 0.00667), were considered as significant thresholds on tstatistics.

To visualize the time evolution of seizures (Tyvaert et al., 2009), hemoglobin concentration changes were computed at each time point (sampling rate of $0.5 \mathrm{~Hz}$ ) relative to a baseline average of the signal at each channel from 25 to $20 \mathrm{~s}$ before the start of the seizure. These concentration changes were then normalized to the time-wise standard deviation of the baseline, and projected with interpolation onto 2dimensional maps. As a compromise between limiting false positives and visualizing the time evolution details, the maps were thresholded to show normalized changes larger in magnitude than 2 . 
Considering a probable small lag between real onset and time to declare for patients who reported auras without surface EEG correlate, several GLM analyses were performed after moving the onsets backward in time (Bagshaw et al., 2004), relative to the fNIRS signals, by multiples of $4 \mathrm{~s}$.

\section{RESULTS}

\section{$\underline{\text { Patient population }}$}

Nine patients (5 males; mean age: 33 years; range: 18 to 64 years) with refractory posterior epilepsies participated in this study. Table 1 summarizes patient demographics and epileptic focus based on multimodal investigation. Table 2 summarizes their EEG-fNIRS study in terms of number of channels used, duration of testing and number of spikes or seizures recorded for each subject.

\section{$\underline{\text { Seizure analysis }}$}

Four patients experienced seizures during EEG-fNIRS recordings (Patients 1, 2, 5 and 7).

Unfortunately, the 2 seizures for patient 5 occurred mostly during 1 minute recording gaps between fNIRS recordings (while EEG is recorded continuously) and the available fNIRS seizure data was too fragmentary for analysis.

Patient 7 had 2 simple partial seizures on EEG lasting $34 \mathrm{~s}$ and $52 \mathrm{~s}$, respectively. GLM analysis of the seizures led to a very significant decrease of $\mathrm{HbR}$ in the left occipital area, concordant with the focus (Fig. 1). The time evolution of both seizures was also analyzed. For seizure 1, the HbR response in the focus area consisted of an initial ( $\sim 30 \mathrm{~s})$ increase in $\mathrm{HbR}$ occurring $20 \mathrm{~s}$ before the earliest EEG changes; concomitantly, a single long decrease of HbR lasting $\sim 30 \mathrm{~s}$ started about $6 \mathrm{~s}$ before EEG seizure onset, which was then followed by a shorter increase in HbR of $20 \mathrm{~s}$ (see Suppl. Movie M1, or Fig. 2 for 10 s-interval snapshots). Later ( $74 \mathrm{~s}$ after the beginning of the seizure on EEG), another HbR 
decrease lasting $\sim 20 \mathrm{~s}$ occurred at the focus, without any obvious EEG correlate. On the other hand, seizure 2 was much weaker at the focus, and showed a contralateral response that was much stronger, featuring spatio-temporal oscillations on time scales of tens of seconds; seizure 2 did not show an initial increase of HbR at the focus, only an initial decrease followed by oscillations (Suppl. Movie M2).

Figures 1 and 2 insert here

A third patient (Patient 1) had numerous (34) brief auras of flashing lights (the onset and offset of each were reported by the patient by lifting and resting the right index finger) without obvious scalp EEG correlate. The result of GLM analyses for onsets moved backward in time by 16, 8, 4 and 0 seconds is shown in Suppl. Fig. S1. A decrease in HbR is visible at the epileptic focus initially at an onset lag of 16 $\mathrm{s}$; this decrease shifts into an increase in $\mathrm{HbR}$ at onset lag of $0 \mathrm{~s}$, when forward spreading of the activity is also manifest.

Similarly, a fourth patient (Patient 2) had a 23 s simple partial seizure (visual phenomena and head lateroflexion) but again with no obvious EEG changes. GLM analysis of this seizure, at the time indicated by the patient, revealed an EC-significant increase in $\mathrm{HbO}$ in the R occipital lobe (Suppl. Fig. S2), broadly consistent with the suspected focus localization for this patient. However, a larger increase was present in the $\mathrm{R}$ frontal lobe. Decreases in $\mathrm{HbO}$ were found in the contralateral homologous areas. No decreases in $\mathrm{HbR}$ were found except in the $\mathrm{R}$ and $\mathrm{L}$ frontal lobes in locations corresponding to the $\mathrm{HbO}$ responses.

Epileptic spike analysis 
Seven out of 9 subjects exhibited interictal spikes during EEG-fNIRS testing (patients 1 and 2 had no spikes). Figures 3 and 4 (Patient 7 and 9) and supplementary figures S3 to S6 (Patients 3 to 6) report individual patients HbR responses to spikes. These responses were broadly sensitive with the patient's epileptic focus in 6/7 patients (see Table 3) and specific in 5/7 patients. For the remaining subject (Patient 8), there were too few spikes for adequate analysis as the recording was prematurely terminated due to helmet discomfort. For 4/7 patients, the large number of spikes suggested nonlinearities could be significant. Nonlinearities were indeed significant in 3/4 patients (Patients 3, 4 and 9, but not in Patient 7) at a t-statistics threshold of 3.0. For completeness, HbO results were presented in Suppl. Table 1: $\mathrm{HbO}$ was seen to be less sensitive (3/7 patients) and specific (1/7 patient) than $\mathrm{HbR}$.

Figures 3 and 4 insert here

In summary, pooling together the seizure and spike observations, the HbR measurements were sensitive to the epileptic focus in $7 / 9$ patients and specific in 5/9.

\section{DISCUSSION}

This preliminary study shows that, using adequate methodological tools, EEG-fNIRS can reveal superficial hemodynamic changes evoked by spikes and seizures in posterior epilepsies. In most of our patients, some response to epileptic activity (seizures or spikes, identified using video-EEG, or from a sign from the patient) could be reported, with various degrees of significance and agreement with the patient's epileptic focus. $\mathrm{HbO}$ responses are more commonly reported than $\mathrm{HbR}$ in the young fNIRS literature, this being due to the $\mathrm{HbO}$ signal being stronger. However, it is expected that $\mathrm{HbR}$ responses reflect better the underlying neuronal phenomena than $\mathrm{HbO}$ (Gagnon et al., 2013, 2011; Kirilina et al., 
2012; Takahashi et al., 2011), especially since HbO is more prone to artefacts due to extracerebral physiological signals. $\mathrm{HbO}$ and $\mathrm{HbT}$ responses were studied and were generally similar but less concordant (meaning sensitive and specific) than HbR responses with respect to the focus. Therefore, the focus was on presenting HbR responses in this work.

To our knowledge, there has been no other report of posterior epilepsies studied by EEG-fNIRS. These findings on posterior epilepsies are in agreement with observations made by our group with temporal (Nguyen et al., 2012) and frontal lobe seizures (Nguyen et al., 2013) as well as interictal spikes (Peng et al., 2013). Indeed, seizures are associated with more substantial hemodynamic changes than single spikes which require averaging or GLM methods similar to what is being done with EEG-fMRI studies (Bénar et al., 2002; Gotman et al., 2006; Salek-Haddadi et al., 2006). Localization of these hemodynamic changes was grossly congruent with the epileptic focus in most patients. As for brief auras/simple partial seizures, it is well known that they may not recruit enough surrounding tissue to be detectable by scalp EEG electrodes (Patients 1 and 2) (Sperling and O'Connor, 1990). In our study, averaging many events (using GLM methodology) allowed congruent gross localization for Patient 1 while inconclusive results were found in Patient 2 who had only one event during testing. Finally, as we observed in all temporal complex partial seizures (Nguyen et al., 2012) and some frontal lobe seizures (Nguyen et al., 2013) previously, large increases in HbR may be seen with posterior seizures (Patient 7) possibly suggesting tissue hypoxia from unmet metabolic demand.

\section{LIMITATIONS}

Our observations obviously remain preliminary considering the following study limitations. For one, most prior fNIRS studies on epilepsy have included only a handful of subjects and our series is no 
different with only 9 subjects. This is partly due to the fact that posterior epilepsies are relatively rare. The high number of channels (and the larger coverage it allowed), the robust statistical analysis and the relative homogeneity of the epileptic condition are however unique to our study. Second, only one patient had clear electroclinical seizures during fNIRS recordings (and the fNIRS response to the 2 seizures of this patient were somewhat different, with seizure 1 being congruent with expectations, and seizure 2 showing a strong contralateral response) while two others had negative-EEG seizures and another had seizures with incomplete fNIRS data. Relying on patient reporting of auras/seizures obviously introduces a potential margin of error. Third, a standard HRF was used as opposed to one specific to each subject, brain location and chromophore (HbR, $\mathrm{HbO})$. Fourth, we cannot exclude potential contribution/contamination of the fNIRS signal from hemoglobin in the skin and extracranial tissue, although this effect is reduced by our consideration of $\mathrm{HbR}$ changes rather than $\mathrm{HbO}$ or $\mathrm{HbT}$ changes. Our future recordings will benefit from additional channels with short source-detector separation which will allow us to subtract this source of contamination (Gagnon et al., 2011).

Several statistical thresholds were considered: EC, Bonferroni, and a threshold of 3.0 on t-statistics. Previous studies have indicated that EC and Bonferroni thresholds may be too severe in practice (Nguyen et al., 2012; Peng et al., 2013). The analog for fNIRS of a false discovery rate (FDR) threshold would be of interest, but its calculation is beyond the scope of this paper (Singh and Dan, 2006; Tak and Ye, 2013). In (Peng et al., 2013), an attempt was made at calculating a peak FDR threshold on 2D maps. Here, as a proxy to a hypothetical FDR threshold, activations exceeding an intermediate t-statistics threshold of 3.0 were considered (corresponding to an uncorrected threshold of 0.00667).

\section{CONCLUSION}


This work adds to the bulk of recent studies exploiting technological developments in fNIRS-EEG to investigate epilepsy. Whether EEG-fNIRS will eventually have some utility in clinical practice remains to be determined. While its resolution will always remain modest and monitoring limited to superficial cortex (limitations which are shared by other techniques as well), our preliminary work suggests it may have some potential for long-term recording, seizure detection, gross localization and characterization of hemodynamic changes associated with spikes and seizures, and impact assessment of focal seizures on tissue oxygenation via $\mathrm{HbR}$ monitoring. Much more technological, methodological and eventually blinded validation work is however necessary.

\section{REFERENCES:}

Adcock, J.E., Panayiotopoulos, C.P., 2012. Occipital lobe seizures and epilepsies. J Clin Neurophysiol 29, 397-407.

Bagshaw, A.P., Aghakhani, Y., Bénar, C.-G., Kobayashi, E., Hawco, C., Dubeau, F., Pike, G.B., Gotman, J., 2004. EEG-fMRI of focal epileptic spikes: analysis with multiple haemodynamic functions and comparison with gadolinium-enhanced MR angiograms. Hum Brain Mapp 22, 179-192.

Bénar, C.G., Gross, D.W., Wang, Y., Petre, V., Pike, B., Dubeau, F., Gotman, J., 2002. The BOLD response to interictal epileptiform discharges. Neuroimage 17, 1182-1192.

Cohen-Adad, J., Chapuisat, S., Doyon, J., Rossignol, S., Lina, J.-M., Benali, H., Lesage, F., 2007. Activation detection in diffuse optical imaging by means of the general linear model. Med Image Anal 11, 616-629.

Duncan, R., Patterson, J., Hadley, D., Roberts, R., 1997. Ictal regional cerebral blood flow in frontal lobe seizures. Seizure 6, 393-401.

Gagnon, L., Perdue, K., Greve, D.N., Goldenholz, D., Kaskhedikar, G., Boas, D.A., 2011. Improved recovery of the hemodynamic response in diffuse optical imaging using short optode separations and state-space modeling. Neuroimage 56, 1362-1371.

Gagnon, L., Yücel, M.A., Boas, D.A., Cooper, R.J., 2013. Further improvement in reducing superficial contamination in NIRS using double short separation measurements. Neuroimage.

Gotman, J., Kobayashi, E., Bagshaw, A.P., Bénar, C.-G., Dubeau, F., 2006. Combining EEG and fMRI: A multimodal tool for epilepsy research. J. Magn. Reson. Imaging 23, 906-920.

Henry, T.R., Van Heertum, R.L., 2003. Positron emission tomography and single photon emission computed tomography in epilepsy care. Semin Nucl Med 33, 88-104.

Irani, F., Platek, S.M., Bunce, S., Ruocco, A.C., Chute, D., 2007. Functional near infrared spectroscopy (fNIRS): an emerging neuroimaging technology with important applications for the study of brain disorders. Clin Neuropsychol 21, 9-37. 
Jenssen, S., Roberts, C.M., Gracely, E.J., Dlugos, D.J., Sperling, M.R., 2011. Focal seizure propagation in the intracranial EEG. Epilepsy Res. 93, 25-32.

Kirilina, E., Jelzow, A., Heine, A., Niessing, M., Wabnitz, H., Brühl, R., Ittermann, B., Jacobs, A.M., Tachtsidis, I., 2012. The physiological origin of task-evoked systemic artefacts in functional near infrared spectroscopy. Neuroimage 61, 70-81.

Li, H., Tak, S., Ye, J.C., 2012. Lipschitz-Killing curvature based expected Euler characteristics for pvalue correction in fNIRS. J. Neurosci. Methods 204, 61-67.

Machado, A., Lina, J.M., Tremblay, J., Lassonde, M., Nguyen, D.K., Lesage, F., Grova, C., 2011. Detection of hemodynamic responses to epileptic activity using simultaneous ElectroEncephaloGraphy (EEG)/Near Infra Red Spectroscopy (NIRS) acquisitions. Neuroimage 56, $114-125$.

Nguyen, D.K., Tremblay, J., Pouliot, P., Vannasing, P., Florea, O., Carmant, L., Lepore, F., Sawan, M., Lesage, F., Lassonde, M., 2012. Non-invasive continuous EEG-fNIRS recording of temporal lobe seizures. Epilepsy Res. 99, 112-126.

Oliveira, A.J., da Costa, J.C., Hilário, L.N., Anselmi, O.E., Palmini, A., 1999. Localization of the epileptogenic zone by ictal and interictal SPECT with 99mTc-ethyl cysteinate dimer in patients with medically refractory epilepsy. Epilepsia 40, 693-702.

Panayiotopoulos, C.P., 1999. Visual phenomena and headache in occipital epilepsy: a review, a systematic study and differentiation from migraine. Epileptic Disord 1, 205-216.

Peng, K., Nguyen, D.K., Tayah, T., Vannasing, P., Tremblay, J., Sawan, M., Lassonde, M., Lesage, F., Pouliot, P., 2013. fNIRS-EEG study of focal interictal epileptiform discharges. Epilepsy Res.

Pouliot, P., Tremblay, J., Robert, M., Vannasing, P., Lepore, F., Lassonde, M., Sawan, M., Nguyen, D.K., Lesage, F., 2012. Nonlinear hemodynamic responses in human epilepsy: a multimodal analysis with fNIRS-EEG and fMRI-EEG. J. Neurosci. Methods 204, 326-340.

Salek-Haddadi, A., Diehl, B., Hamandi, K., Merschhemke, M., Liston, A., Friston, K., Duncan, J.S., Fish, D.R., Lemieux, L., 2006. Hemodynamic correlates of epileptiform discharges: an EEGfMRI study of 63 patients with focal epilepsy. Brain Res. 1088, 148-166.

Singh, A.K., Dan, I., 2006. Exploring the false discovery rate in multichannel NIRS. Neuroimage 33, 542-549.

Tak, S., Ye, J.C., 2013. Statistical analysis of fNIRS data: A comprehensive review. Neuroimage.

Takahashi, T., Takikawa, Y., Kawagoe, R., Shibuya, S., Iwano, T., Kitazawa, S., 2011. Influence of skin blood flow on near-infrared spectroscopy signals measured on the forehead during a verbal fluency task. Neuroimage 57, 991-1002.

Tandon, N., Alexopoulos, A.V., Warbel, A., Najm, I.M., Bingaman, W.E., 2009. Occipital epilepsy: spatial categorization and surgical management. J. Neurosurg. 110, 306-318.

Tyvaert, L., LeVan, P., Dubeau, F., Gotman, J., 2009. Noninvasive dynamic imaging of seizures in epileptic patients. Hum Brain Mapp 30, 3993-4011.

Van Paesschen, W., 2004. Ictal SPECT. Epilepsia 45 Suppl 4, 35-40.

Williamson, P.D., Thadani, V.M., Darcey, T.M., Spencer, D.D., Spencer, S.S., Mattson, R.H., 1992. Occipital lobe epilepsy: clinical characteristics, seizure spread patterns, and results of surgery. Ann. Neurol. 31, 3-13.

Ye, J.C., Tak, S., Jang, K.E., Jung, J., Jang, J., 2009. NIRS-SPM: statistical parametric mapping for near-infrared spectroscopy. Neuroimage 44, 428-447. 


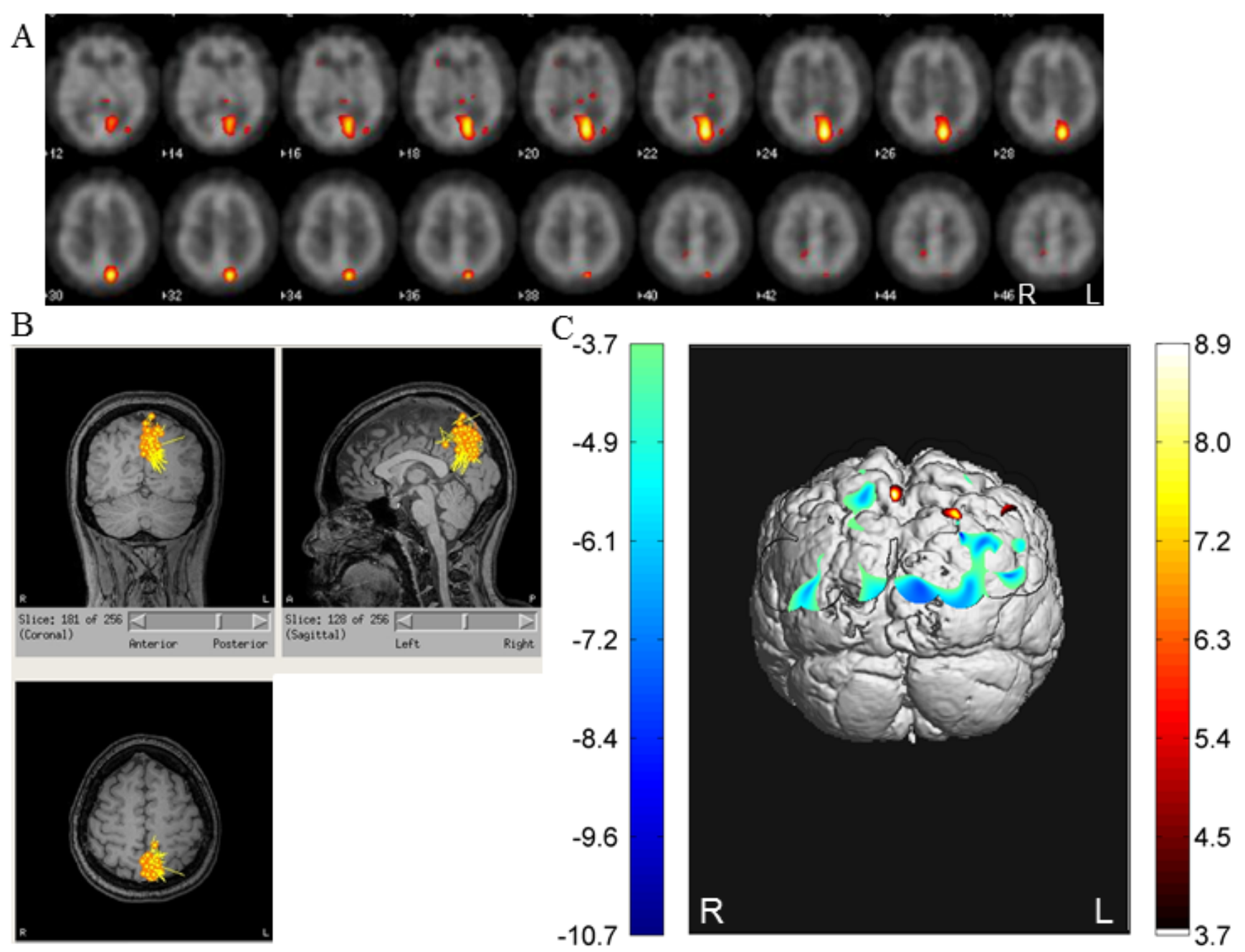

Figure 1 (Patient 7): 19 yo with daily seizures characterized by diplopia, R oculocephalic deviation with or without altered consciousness and occasional tonic posturing. MRI was normal but ictal SPECT, PET and MEG all identified a concordant L parieto-occipital focus. Ictal EEG showed rhythmic theta activity over both occipital regions. A. iSPECT. B. MEG. C. fNIRS. GLM HbR responses of the first seizure showing a decrease in the L occipital lobe congruent with the epileptic focus (EC threshold: 3.9 ). 


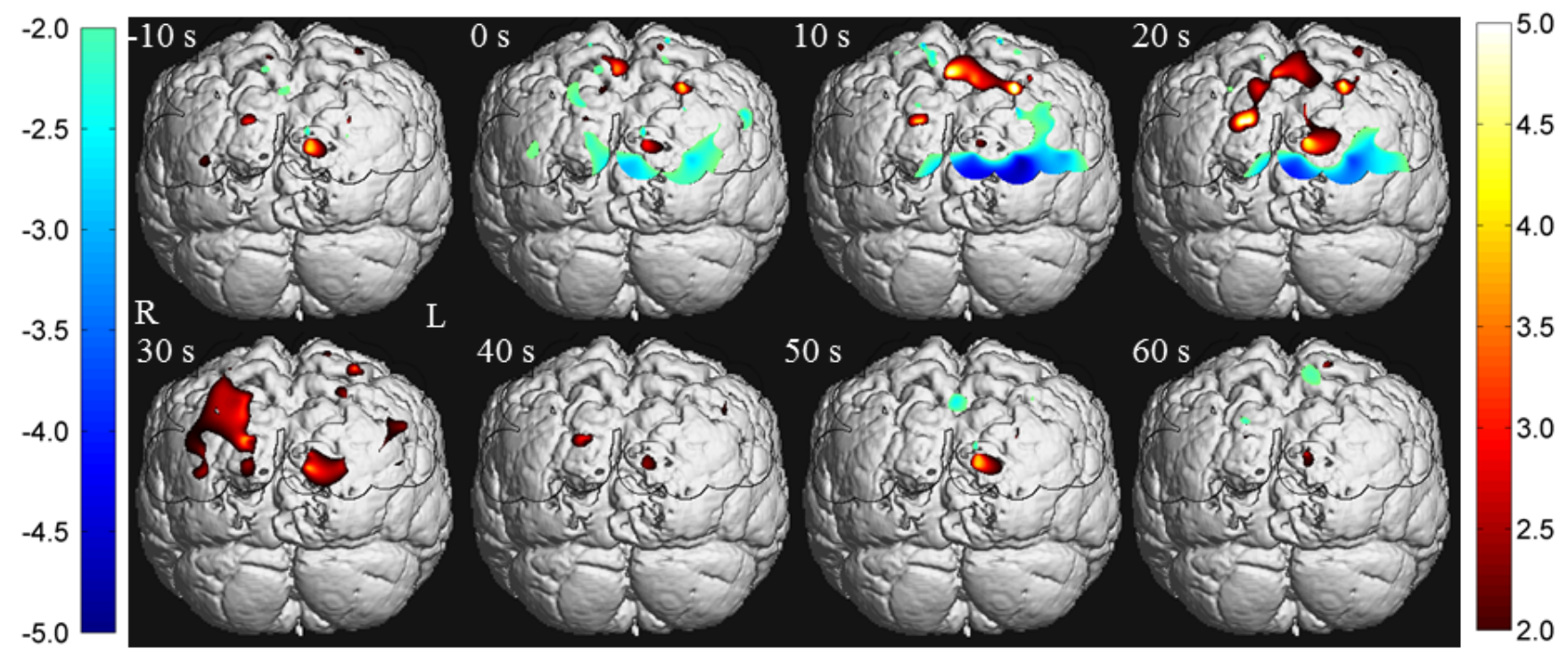

Figure 2 (Patient 7, seizure 1) : HbR concentration changes relative to baseline (calculated between -25 and $-20 \mathrm{~s}$ before first seizure), and scaled by the time-wise standard deviation of the baseline data, in 10 $\mathrm{s}$ increments from top left, starting $10 \mathrm{~s}$ before the first seizure. A $10 \mathrm{~s}$ increase in HbR was followed by a long $30 \mathrm{~s}$ decrease, then by a shorter ( $20 \mathrm{~s}$ ) increase (Note scales were fixed between \pm 2 and \pm 5 ). 


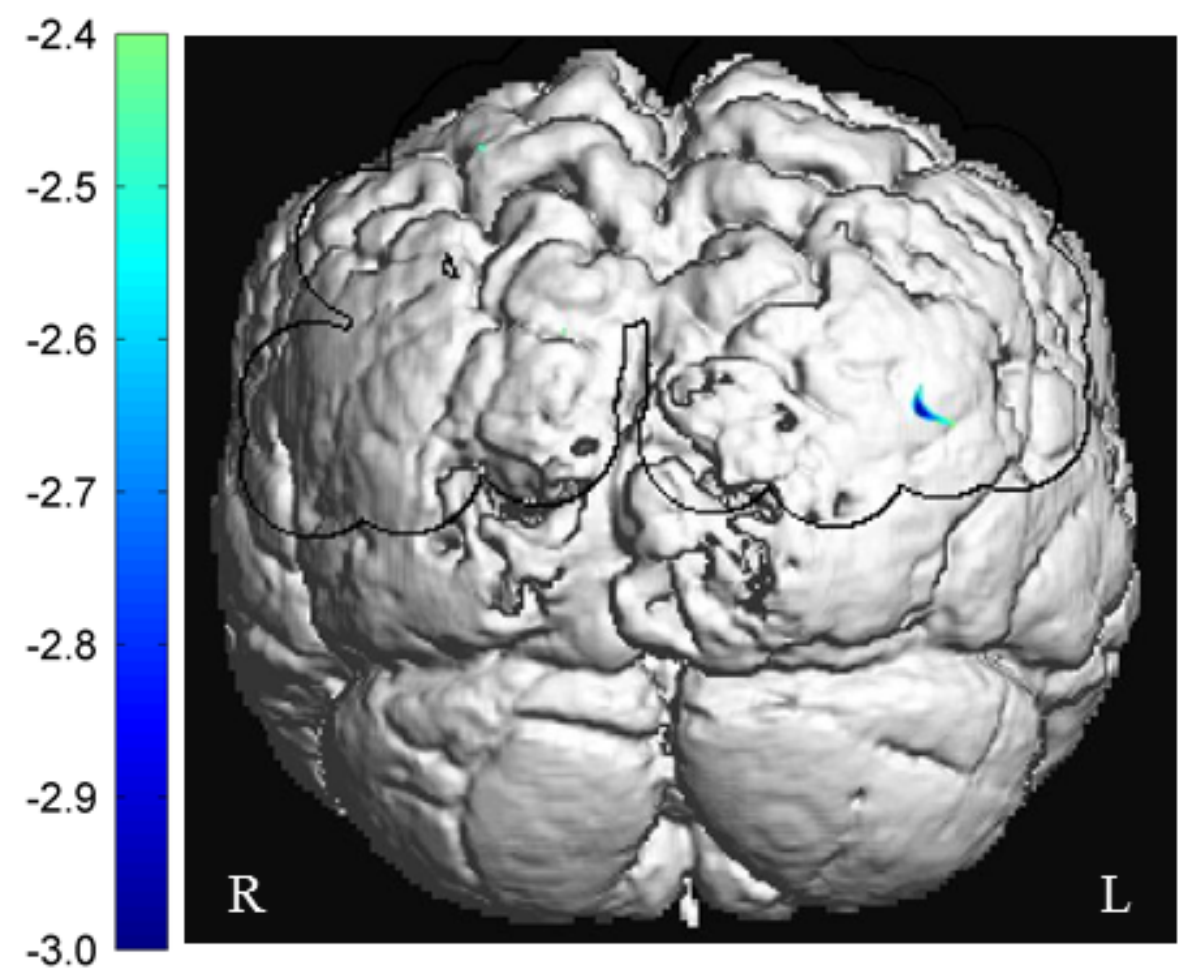

Figure 3 (Patient 7, same as in Fig. 1 and 2). 446 left or bilateral occipital discharges were identified during four 15-minute sessions. GLM analysis of the epileptic spikes produced a small decrease of HbR that is close to epileptic focus (slightly too lateral by $\sim 2 \mathrm{~cm}$ ). 


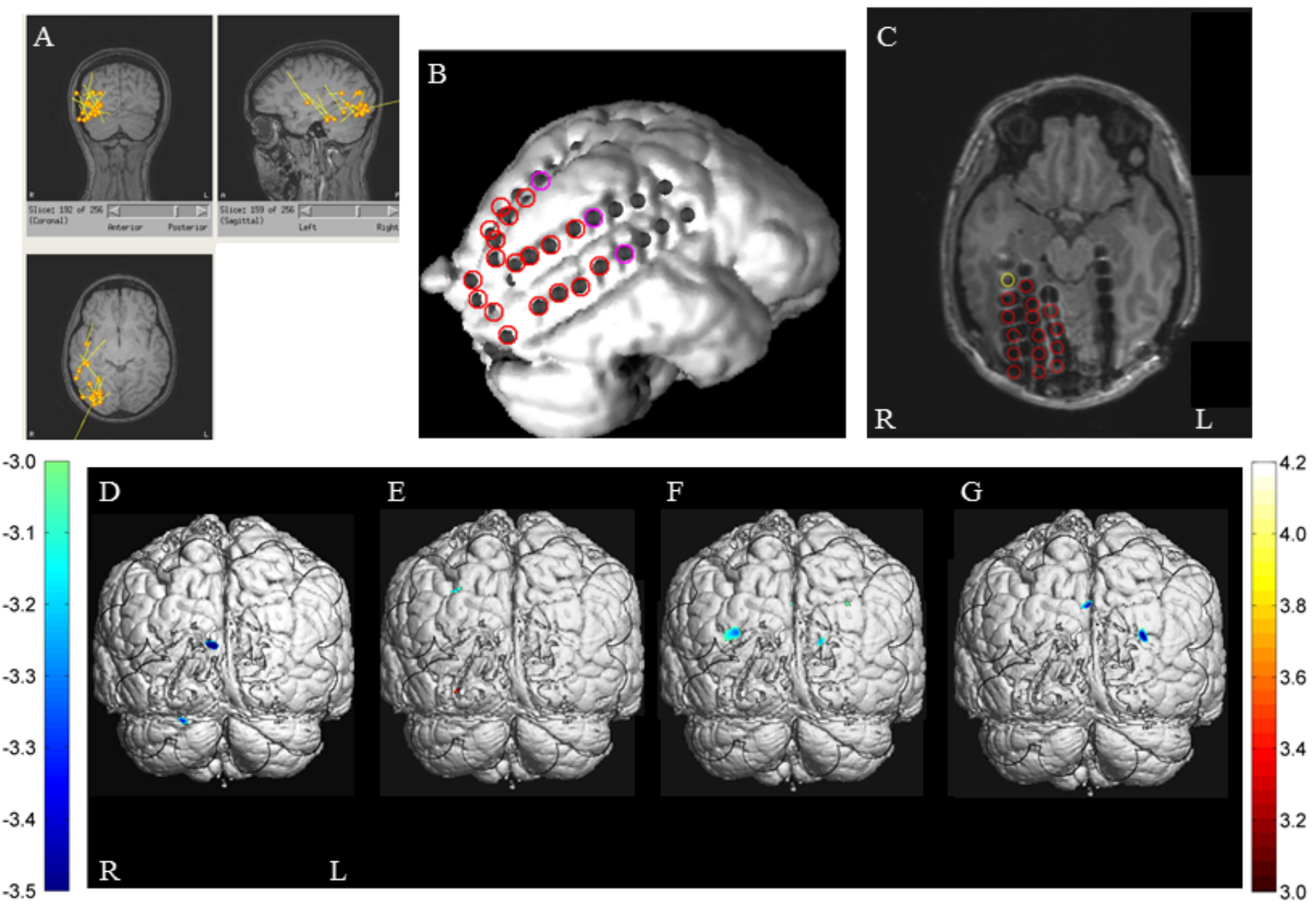

Figure 4 (Patient 9): 25 yo woman presenting, since age 13, episodes with or without flashing lights in the $\mathrm{L}$ or R visual field with or without altered consciousness and rare convulsions. Investigations included a normal MRI and PET. EEG showed very active bilateral independent parieto-temporooccipital (PTO) spikes, isolated or in bursts, with occasional bilateral secondary synchrony. Independent $\mathrm{L}$ and $\mathrm{R}$ posterior quadrant seizures were recorded as well. A. MEG source localizations using electrical current dipole modeling. B and C. Intracranial EEG study: red circles indicate electrodes with epileptic activity at seizure onset. D to G. fNIRS. During EEG-fNIRS, 968 bilateral and 253 right PTO discharges, along with 181 isolated generalized spike-wave discharges (GSW) and 101 GSW bursts, were identified during three 15-minute sessions. GLM analysis led to several distinct occipital responses, with associated nonlinearities: D- for GSW bursts, a right cuneus HbR decrease, with significant inhibitive nonlinearities; E- for isolated GSWs, a weak RO HbR decrease; F- for R PTO 
spikes, a bilateral occipital HbR decrease; G- for biPTO spikes, a weaker bilateral occipital HbR decrease (EC threshold: 3.9; Bonferroni threshold: 3.4). 


\begin{tabular}{|c|c|c|c|c|c|c|c|c|}
\hline Patient & \begin{tabular}{|l|} 
Age \\
(yr)
\end{tabular} & Gender & $\begin{array}{c}\text { Onset } \\
\text { (yr) }\end{array}$ & $\begin{array}{c}\mathrm{Sz} \\
\text { frequency }\end{array}$ & Neurophysiology & MRI & SPECT & Focus \\
\hline 1 & 52 & $\mathrm{~F}$ & 17 & $d^{*}$ & EEG: Normal & R O cavernoma & $\mathrm{R} \mathrm{O}>\mathrm{R} \mathrm{LT}$ & R O \\
\hline 2 & 24 & $\bar{M}$ & 15 & $\bar{d}$ & EEG: biO R>L & Negative & $\uparrow \mathrm{R} \mathrm{O}>\mathrm{P}$ & $\mathrm{RO}$ \\
\hline 3 & 21 & $\mathrm{~F}$ & 14 & $\mathrm{~d}$ & $\begin{array}{c}\text { EEG + icEEG: L } \\
\text { OPT }\end{array}$ & L OP tuber & $\uparrow \mathrm{L}$ OT & L OPT \\
\hline 4 & 17 & M & 15 & $\mathrm{w}$ & $\begin{array}{c}\text { EEG: } \mathrm{R} \text { hemispheric } \\
\max \mathrm{T}\end{array}$ & R TO cavernoma & $\uparrow \mathrm{R} \mathrm{T}$ & $\begin{array}{l}\text { R TO } \\
\text { junction }\end{array}$ \\
\hline 5 & 18 & $\mathrm{M}$ & 9 & $\mathrm{w}$ & EEG + icEEG: R OT & Negative & $\uparrow R O T$ & R OT \\
\hline 6 & 63 & M & 55 & $\mathrm{~m}$ & EEG: RO & \begin{tabular}{|c|} 
R OP post- \\
hemorrhagic \\
encephalomalacia
\end{tabular} & NA & R OP \\
\hline 7 & 19 & $\mathrm{~F}$ & 4 & $d$ & $\begin{array}{l}\text { EEG: biOP L>R; } \\
\text { MEG: L PO) }\end{array}$ & Negative & $\uparrow$ LOP & L OP \\
\hline 8 & 15 & $\mathrm{~F}$ & 9 & $\mathrm{~d}$ & $\begin{array}{c}\text { EEG: Diffuse, } \\
\text { maximum biO L }>\text { R }\end{array}$ & L PO DNET & NA & L PO \\
\hline 9 & 25 & $\mathrm{~F}$ & 13 & $\mathrm{~d}$ & $\begin{array}{l}\text { EEG: bi OTP R>L; } \\
\text { MEG: R OT }\end{array}$ & Negative & Multiple & R OTP \\
\hline
\end{tabular}

Table. 1 Patient characteristics. Legend: $\mathrm{d}=$ daily; $\mathrm{w}=$ weekly; $\mathrm{m}=$ monthly; $\mathrm{R}=$ right; $\mathrm{L}=$ left; $\mathrm{O}=$ occipital; $\mathrm{P}=$ parietal; $\mathrm{T}=$ temporal. * one month-long cluster of seizures every year; $\mathrm{EEG}=$ scalp electroencephalography; icEEG = intracranial EEG; $\mathrm{MEG}=$ magnetoencephalography; SPECT = ictal single photon emission computed tomography. DNET $=$ Dysembryoplastic neuroepithelial tumor. 


\begin{tabular}{|c|c|c|c|c|c|}
\hline Patient & $\begin{array}{c}\text { Number of } \\
\text { Channels }\end{array}$ & $\begin{array}{c}\text { Number } \\
\text { of } \\
\text { Sessions }\end{array}$ & $\begin{array}{c}\text { fNIRS } \\
\text { duration } \\
\text { (minutes) }\end{array}$ & Epileptic Events & $\begin{array}{c}\text { fNIRS analysis } \\
\text { performed on }\end{array}$ \\
\hline $\mathbf{1}$ & 135 & 5 & 76 & 34 (signs from patient) & non-EEG seizures \\
\hline $\mathbf{2}$ & 129 & 4 & 61 & 1 seizure (23 s) & non-EEG seizure \\
\hline $\mathbf{3}$ & 107 & 3 & 46 & 1157 L OPT spikes & $\begin{array}{c}\text { spikes (nonlinearities } \\
\text { studied) }\end{array}$ \\
\hline $\mathbf{4}$ & 106 & 6 & 83 & $\begin{array}{c}\text { 666 RT, 530 RFCPT } \\
\text { spikes }\end{array}$ & $\begin{array}{c}\text { spikes (merged into } \\
\text { same type; } \\
\text { nonlinearities studied) }\end{array}$ \\
\hline $\mathbf{5}$ & 47 & 20 & 20 & $\begin{array}{c}\text { 2 seizures, 21 R OT } \\
\text { spikes }\end{array}$ & $\begin{array}{c}\text { spikes (seizures } \\
\text { incompletely recorded) }\end{array}$ \\
\hline $\mathbf{6}$ & 173 & 3 & 46 & 39 RO spikes & spikes \\
\hline $\mathbf{7}$ & 135 & 4 & 61 & $\begin{array}{c}\text { 2 seizures (34 and 52 s), } \\
\text { 446 L OP or biOP }\end{array}$ & $\begin{array}{c}\text { seizures; spikes } \\
\text { (nonlinearities studied) }\end{array}$ \\
\hline $\mathbf{8}$ & 122 & 1 & 13 & 4 L PO spikes & $\begin{array}{c}\text { spikes (insufficient } \\
\text { number) }\end{array}$ \\
\hline $\mathbf{9}$ & 142 & 3 & 46 & $\begin{array}{c}\text { 186 bi OPT, 253 R OPT, } \\
\text { bursts }\end{array}$ & $\begin{array}{c}\text { 4 types of spikes } \\
\text { (nonlinearities studied) }\end{array}$ \\
\hline
\end{tabular}

Table.2 EEG-fNIRS recordings. Legend: $\mathrm{R}=$ right; $\mathrm{L}=$ left; $\mathrm{bi}=$ bilateral; $\mathrm{O}=$ occipital; $\mathrm{P}=$ parietal; $\mathrm{T}$ $=$ temporal; $\mathrm{F}=$ frontal; GSW $=$ generalized spike wave discharges. 


\begin{tabular}{|c|c|c|c|c|}
\hline Patient & GLM Analysis Results (for HbR) & Threshold & Sensitivity & Specificity \\
\hline 1 & $\begin{array}{c}\text { RO HbR decrease (with HRF shifted back } \\
\text { by } 16 \text { seconds) }\end{array}$ & $\mathrm{EC}$ & Yes & No \\
\hline 2 & no HbR decrease & Any & No & No \\
\hline 3 & LTO HbR decrease with nonlinearities & $\mathrm{EC}$ & Yes & No \\
\hline 4 & RTO HbR decrease with nonlinearities & Bonferroni & Yes & Yes \\
\hline 5 & $\begin{array}{l}\text { RTO (primary focus) and R posterior } \\
\text { (secondary focus) HbR decrease }\end{array}$ & Bonferroni & Yes & Yes \\
\hline 6 & RTO HbR decrease & $\mathrm{EC}$ & Yes & Yes \\
\hline 7 & LO HbR decrease & $\mathrm{t} \geq 3.0$ & Yes & $\begin{array}{l}\text { Yes for spikes, } \\
\text { No for seizures }\end{array}$ \\
\hline 8 & insufficient data & - & - & - \\
\hline 9 & biO $\mathrm{HbR}$ decrease with nonlinearities & $\mathrm{EC}$ & Yes & $\begin{array}{c}\text { Yes for GSW } \\
\text { bursts, No for the } \\
\text { other } 3 \text { spike } \\
\text { types }\end{array}$ \\
\hline
\end{tabular}

Table. 3 fNIRS HbR results summary 
Supplementary data: patient descriptions and fNIRS results

\begin{tabular}{|c|c|c|c|c|}
\hline Patient & GLM Analysis Results (for HbO) & Threshold & Sensitivity & Specificity \\
\hline 1 & $\begin{array}{l}\text { RO HbO increase (with HRF shifted back } \\
\text { by } 8 \text { seconds) }\end{array}$ & $\mathrm{EC}$ & Yes & No \\
\hline 2 & $\mathrm{RO} \mathrm{HbO}$ increase & $\mathrm{EC}$ & Yes & $\begin{array}{l}\text { No (frontal } \\
\text { response, not } \\
\text { shown) }\end{array}$ \\
\hline 3 & LTO HbO increase with nonlinearities & $\mathrm{EC}$ & Yes & No \\
\hline 4 & $\begin{array}{l}\text { RTO HbO decrease (wrong sign) with } \\
\text { nonlinearities (and contralateral HbO } \\
\text { increases, with nonlinearities) }\end{array}$ & Bonferroni & No & No \\
\hline 5 & $\begin{array}{l}\text { R posterior (secondary focus) } \mathrm{HbO} \text { increase } \\
\text { (but RTO (primary focus) HbO increase not } \\
\text { significant) }\end{array}$ & Bonferroni & Yes & Yes \\
\hline 6 & No activations & Any & No & No \\
\hline 7 & $\begin{array}{l}\text { For spikes: only activations contralateral to } \\
\text { focus (HbO increase); for seizures: bilateral } \\
\text { HbO increase }\end{array}$ & $\mathrm{t} \geq 3.0$ & $\begin{array}{l}\text { No for spikes, } \\
\text { Yes for } \\
\text { seizures }\end{array}$ & No \\
\hline 8 & insufficient data & - & - & - \\
\hline 9 & biO HbO incease with nonlinearities & $\mathrm{EC}$ & Yes & No \\
\hline
\end{tabular}

Supplementary Table.1 fNIRS HbO results summary 
Pouliot et al. 24
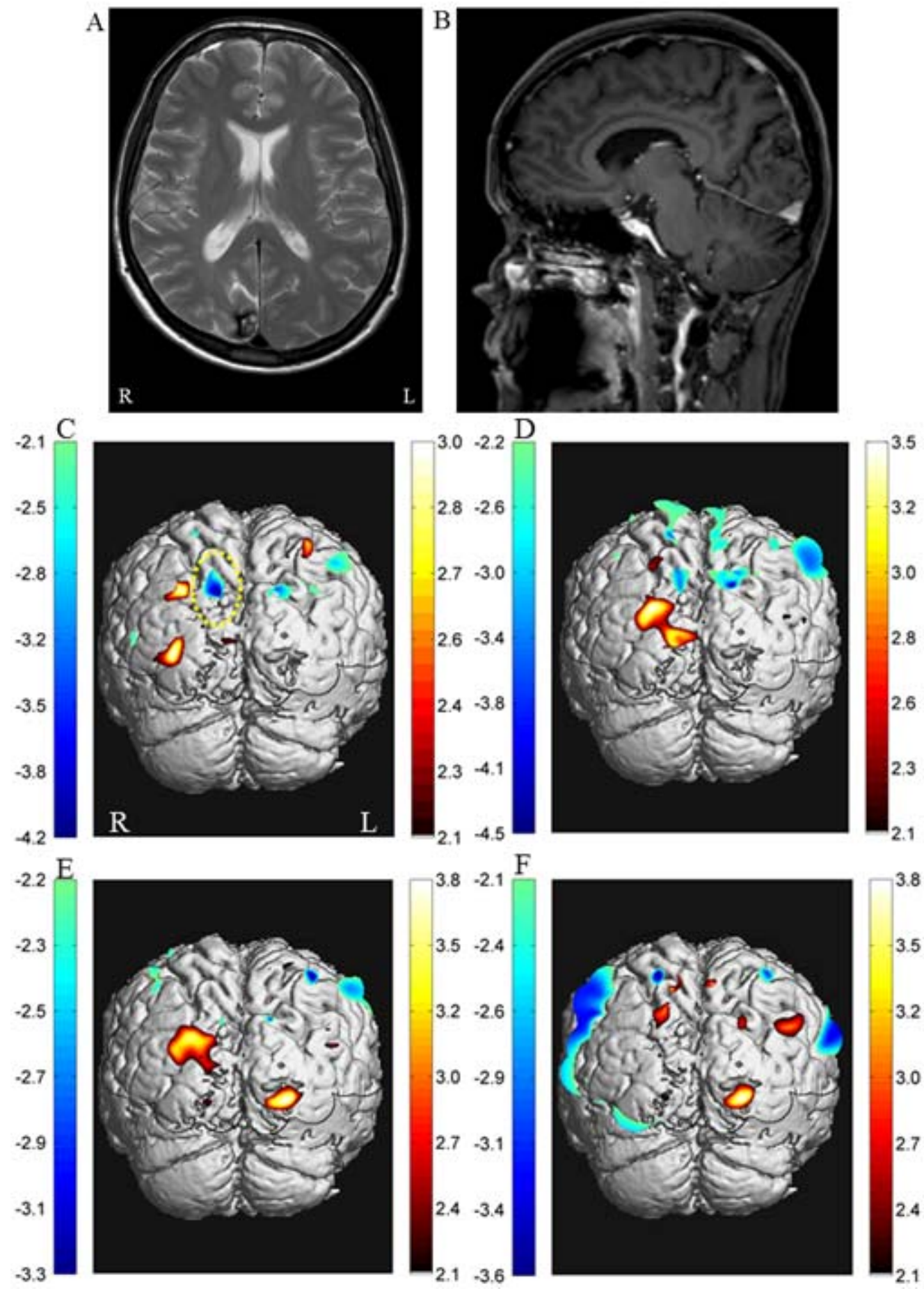

Supplementary Figure S1 (Patient 1): 52 yo woman with yearly catamenial seizure clusters lasting a week since age 17 years related to R occipital cavernoma. During clusters, she would experience $\sim 30 \mathrm{~s}$ episodes of left lower quadrant phosphenes every 5 minutes (culminating into convulsions four times in 
her lifetime) and with postictal quadranopia and headaches. Continuous EEG monitoring showed no epileptic activity during or in-between episodic phosphenes. A. and B. Axial and sagittal MRI cuts showing the R occipital cavernoma. C to F. fNIRS. Recordings of five 15 minute sessions were made, during which 34 visual auras were reported by the patient, lasting from 2 to 87 seconds, and $20 \pm 27 \mathrm{~s}$ on average. Since video evidence of epileptic activity was likely to be a lagged indicator, several GLM analyses were performed using these instances as onsets, moved backward in time by 16 (C), 8 (D), 4 (E) and 0 (F) seconds. A decrease in HbR is visible at the epileptic focus initially at an onset lag of $16 \mathrm{~s}$; this decrease shifts into an increase in $\mathrm{HbR}$ at onset lag of $0 \mathrm{~s}$, when forward spreading of the activity is also manifest (Note different scales; EC threshold: 3.3; Epileptic focus outlined in yellow in C). 


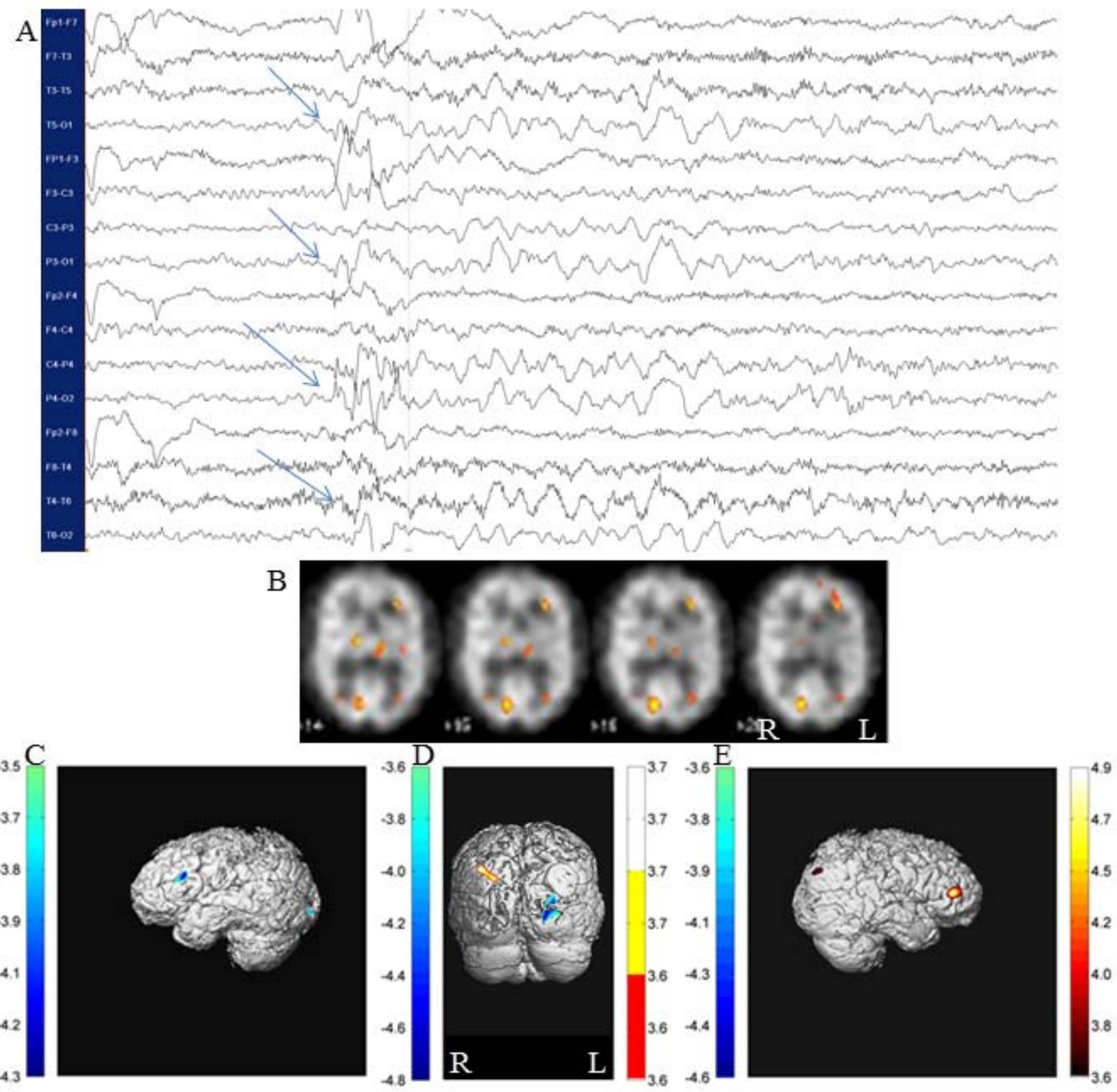

Supplementary Figure S2 (Patient 2): 24 yo man with nonlesional R refractory occipital epilepsy since age 15 manifesting as daily 10-20 s episodes of blurred/loss of vision with or without head lateroflexion, limb automatisms or extension and occasionally momentary lapse of consciousness. A. Video-EEG monitoring showed occasional $\mathrm{R}$ interictal occipital sharp waves. Brief spells were not associated with 
clear epileptic activity but longer spells were associated with rhythmic/semi-rhythmic theta activity in both posterior quadrants. Ictal SPECT showed R occipito-parietal activation. B. SPECT. C (left), D (occipital), E (right view). fNIRS. GLM analysis of the 23 s seizure captured during fNIRS testing revealed an EC-significant increase in $\mathrm{HbO}$ in the $\mathrm{R}$ occipital lobe as well. However, a larger increase was present in the $\mathrm{R}$ frontal lobe. Decreases in $\mathrm{HbO}$ were found in the contralateral homologous areas. No decreases in HbR were found except in the $\mathrm{R}$ and $\mathrm{L}$ frontal lobes in locations corresponding to the $\mathrm{HbO}$ responses (Note different scales. EC threshold: 3.6). 
Pouliot et al. 28
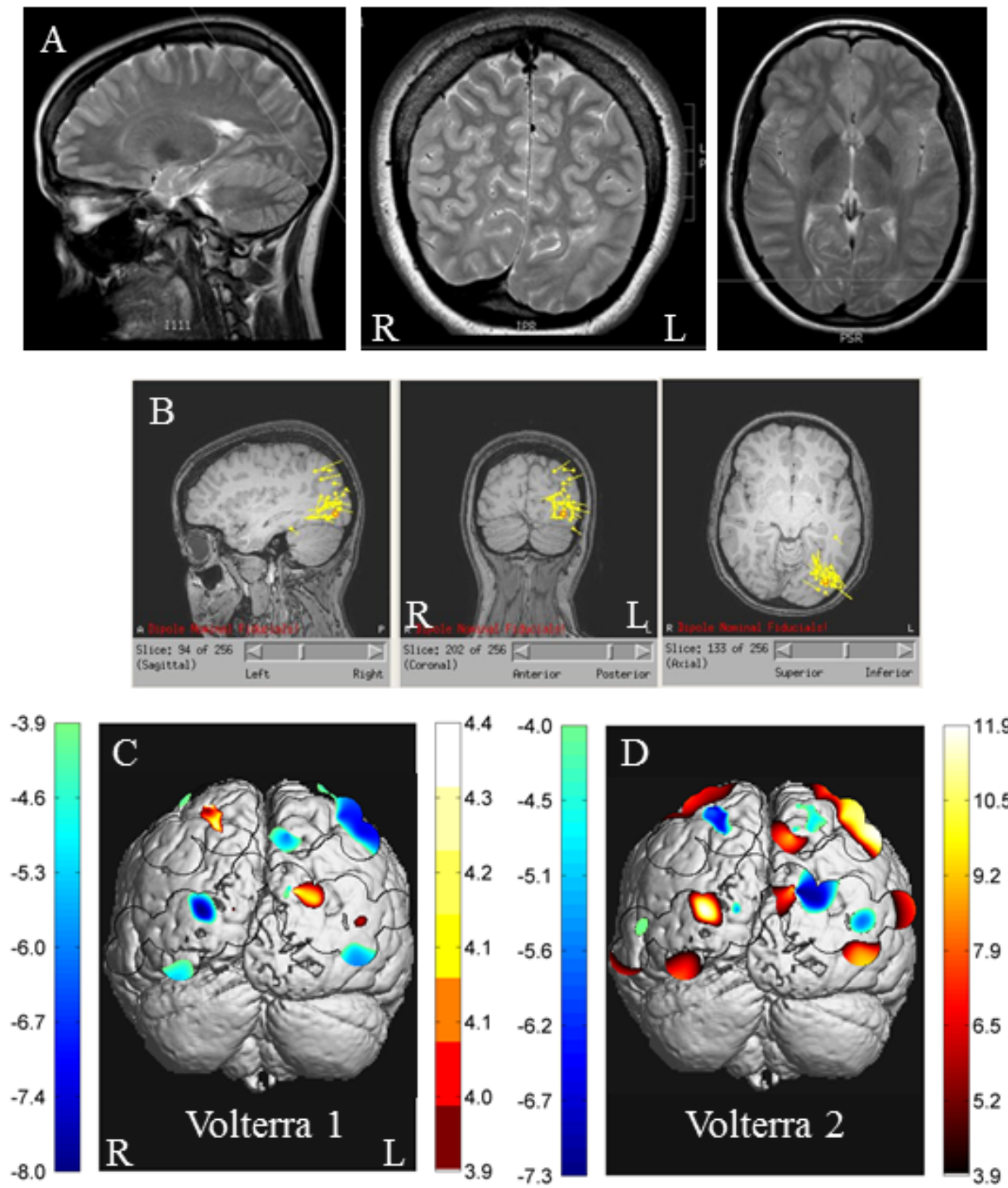

Supplementary Figure S3 (Patient 3): 21 yo woman with tuberous sclerosis seizure-free following a L parieto-occipital corticectomy guided by invasive EEG which showed early L parieto-occipital onset and very quick propagation to posterior temporal regions (FU >3years). A. Sagittal, coronal and axial MRI cuts showing the epileptogenic tuber at the left parieto-occipital junction. B. Sagittal, coronal and axial MEG source localizations. C, D and E. fNIRS. The GLM analysis of L occipital spikes captured during 
the presurgical EEG-fNIRS study showed a strong decrease in HbR at the LPO junction for the $1^{\text {st }}$ Volterra regressor (C) and a corresponding opposite sign nonlinear contribution (D) indicating inhibition of the linear response (EC threshold: 3.9). There was also a strong decrease of HbR in the R cuneus, and thus the GLM results were not specific. This is an updated analysis of the third patient previously reported in (Pouliot et al., 2012), where the old analysis had been done on a much restricted number of channels. 

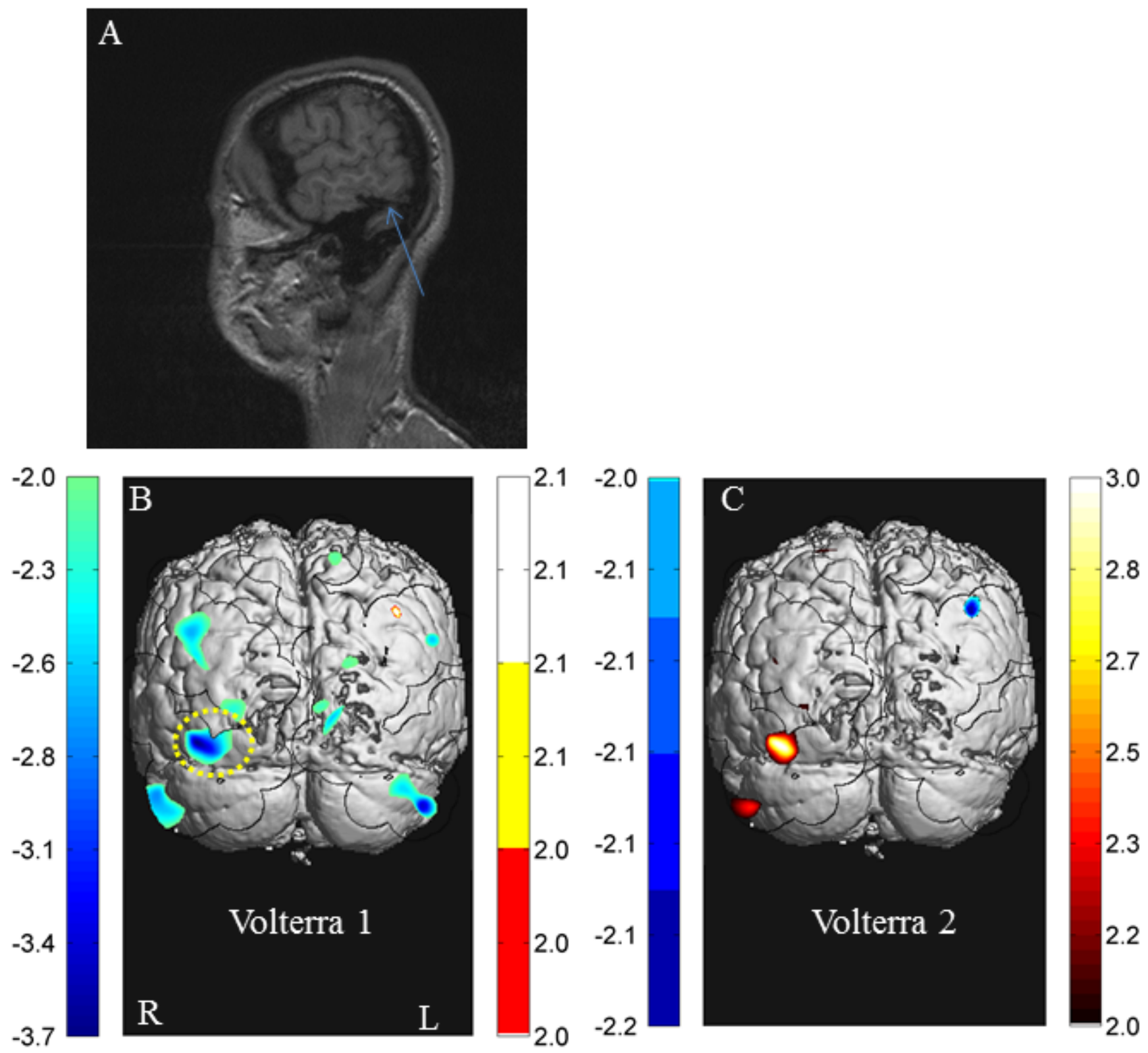

Supplementary Figure S4 (Patient 4): 17 yo patient with refractory epilepsy related to a cavernoma at the

$\mathrm{R}$ temporo-occipital junction with episodes of palinopia with or without altered consciousness. A. Sagittal MRI cut showing the hemosiderin deposit at the temporo-occipital junction. B and C. fNIRS. The GLM analysis clearly identified the focus at the $\mathrm{R}$ temporo-occipital junction as the location with the largest decrease in $\mathrm{HbR}$ for the $1^{\text {st }}$ Volterra regressor $(\mathrm{B})$ combined with an increase in $\mathrm{HbR}$ in the 
Pouliot et al. 31

$2^{\text {nd }}$ Volterra regressor $(C)$. This HbR response was specific. Similarly located activations were seen in $\mathrm{HbO}$ and $\mathrm{HbT}$, with the opposite sign as expected (Note different scales; Bonferroni threshold: 3.2). 

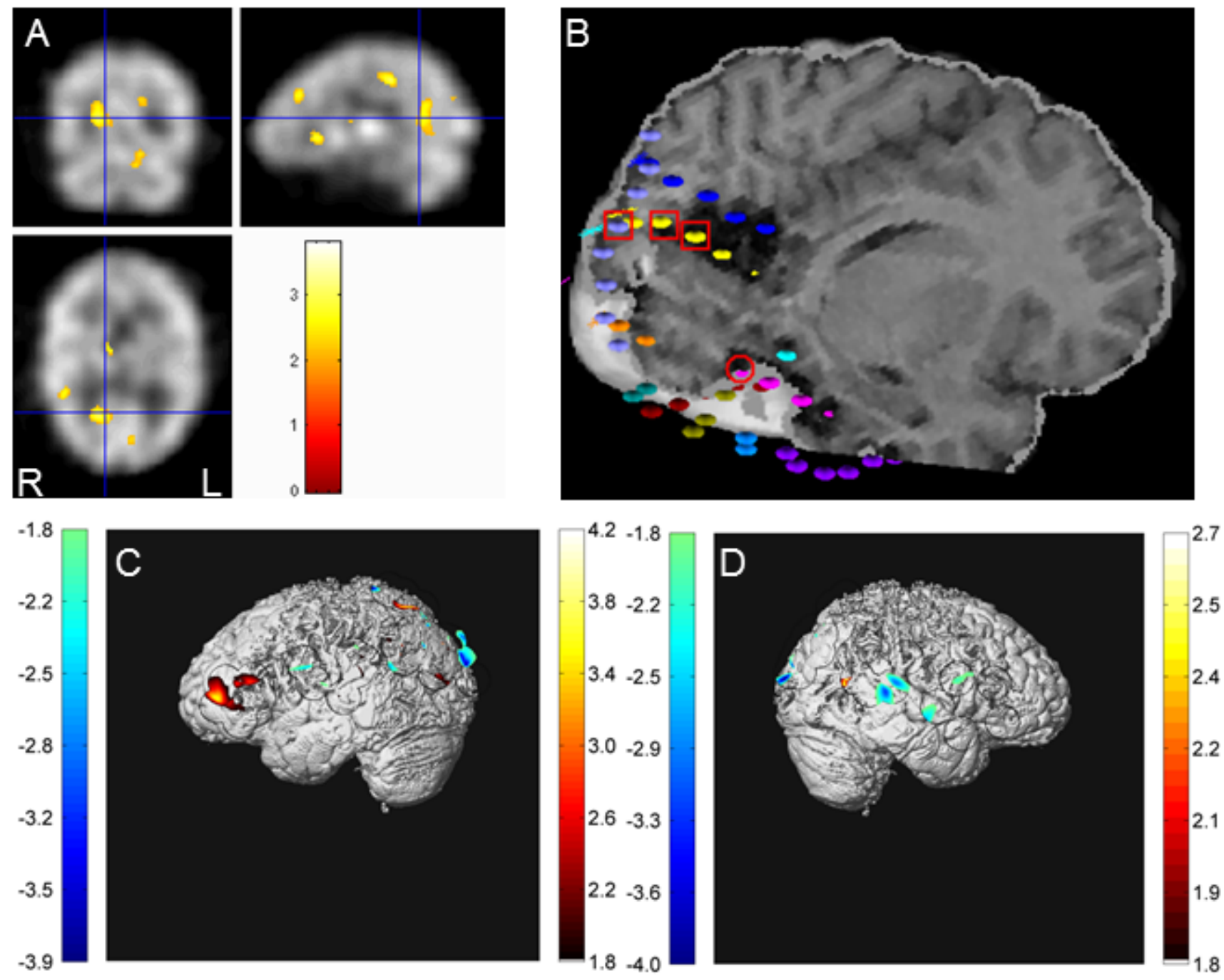

Supplementary Figure S5 (Patient 5): 18 yo male now seizure-free following an extensive R occipital resection (FU 5 years) guided by intracranial EEG. A. Ictal SPECT showing increased perfusion in the right occipital lobe during a seizure. B. intracranial EEG showed two areas of seizure onsets, the first (red and squares) in the right superior occipital gyrus-precuneus area and the second (red circle) at the temporo-occipital junction. C (left view) and D (right view). fNIRS. While 2 seizures were recorded on EEG, they occurred mostly during fNIRS recording gaps, and did not lead to fNIRS responses. The GLM analysis of 21 epileptic spikes led to a concordant response for HbR: a decrease at the R occipital 
lobe and the R posterior temporal area (Bonferroni threshold: 3.2). This HbR response was specific. The $\mathrm{HbO}$ response (not shown) was sensitive only to the posterior seizure onset area, but not to the T-O junction area. 

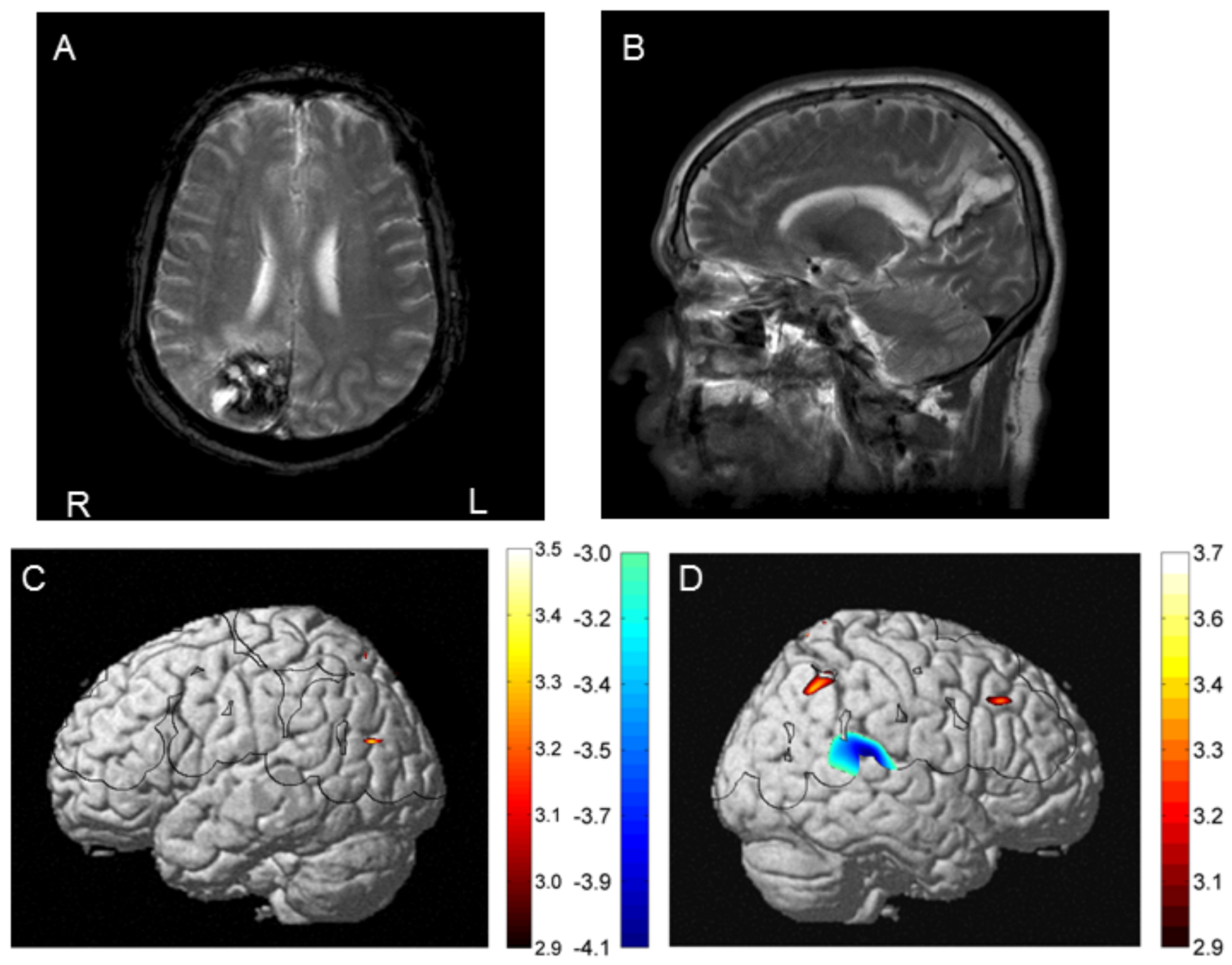

Supplementary Figure S6 (Patient 6): 63 yo patient with seizures related to a previous R hypertensive parieto-occipital hemorrhage. A and B. Axial and Sagittal MRI cuts showing the epileptogenic lesion. C (left view) and D (right view). fNIRS. 39 R temporo-occipital spikes were identified in three 15 minutes fNIRS sessions. An EC-significant decrease in $\mathrm{HbR}$ was found ipsilaterally at the temporo-occipital border of the encephalomalacic area (EC threshold: 3.9). This HbR response was specific. No significant responses were found for $\mathrm{HbO}$ (not shown), except in session 2, where an increase was found at the parieto-occipital junction, surrounded by decreases. 


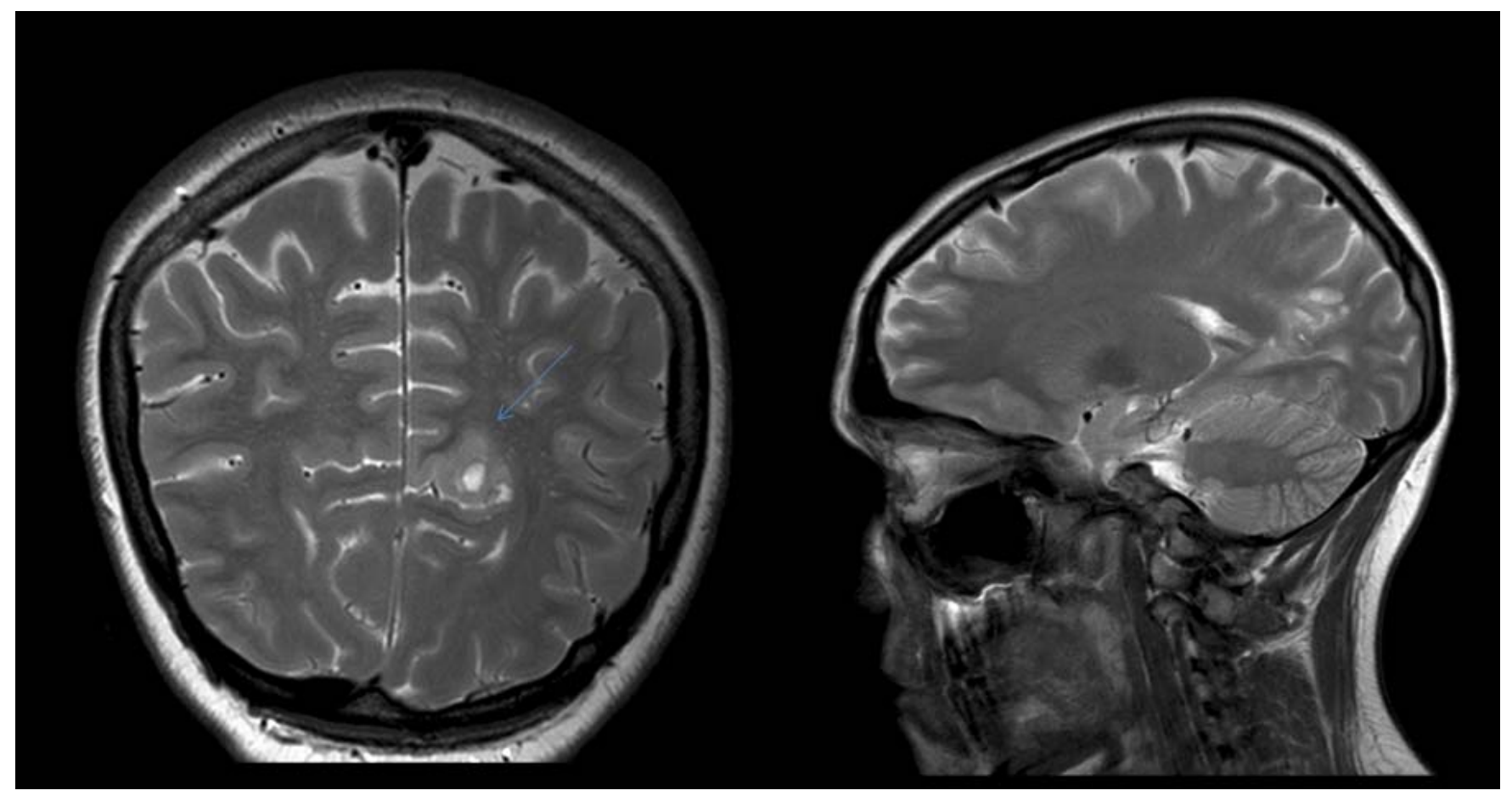

Supplementary Figure S7 (Patient 8): This 15 yo female with L parieto-occipital epilepsy since age 10 yo related to a L medial PO dysembryoplastic neuroepithelial tumour (arrow). EEG reveals L PO spikes. 